\title{
Determinação da compatibilidade de desenvolvimento de culturas bacteriocinogênicas e fermento láctico
}

\author{
Determination of the growth compatibility between bacteriocinogenic and starter cultures
}

Maristela da Silva do NASCIMENTO ${ }^{1,2 *}$, Izildinha MORENO²$^{2}$, Arnaldo Yoshiteru KUAYE ${ }^{1}$

\begin{abstract}
Resumo
Além da utilização como bioconservantes de alimentos, algumas culturas bacteriocinogênicas estão sendo empregadas para acelerar a maturação de queijos. Porém a compatibilidade de desenvolvimento destas culturas com o fermento láctico é essencial para a obtenção de produtos característicos. O objetivo deste estudo foi avaliar a compatibilidade de desenvolvimento de Lactococcus lactis subsp. lactis ATCC 11454, Lactobacillus plantarum ALC 01 e Enterococcus faecium FAIR-E 198 com duas marcas comerciais de fermentos lácticos. Inicialmente, foi determinada a sensibilidade in vitro dos fermentos às culturas bacteriocinogênicas, somente Lc. lactis subsp. lactis ATCC 11454 foi capaz de promover a inibição de ambos os fermentos. Durante desenvolvimento associativo em leite a $35^{\circ} \mathrm{C}$, as culturas bacteriocinogênicas não afetaram significativamente a produção de ácido láctico pelos fermentos. Estes, por sua vez proporcionaram aumento significativo da atividade de pediocina AcH e enterocina FAIR-E 198 e supressão da atividade da nisina. Dentre todas as culturas lácticas, $L b$. plantarum ALC 01 apresentou a maior atividade de aminopeptidases (0,226 a 0,390). Portanto, baseado nos resultados em questão, Lb. plantarum ALC 01 e E. faecium FAIR-E 198 apresentam características de compatibilidade de desenvolvimento com o fermento mesofílico tipo O para serem empregadas como adjuntas no processamento de queijos.
\end{abstract}

Palavras-chave: bacteriocina; aminopeptidase; queijo.

\begin{abstract}
In addition to being used as food bioconservants, some bacteriocinogenic cultures have been employed to accelerate cheese ripening. However, the compatibility between their growth and starter cultures is essential to obtain the characteristic products. The purpose of this study was to evaluate the growth compatibility between Lactococcus lactis subsp. lactis ATCC 11454, Lactobacillus plantarum ALC 01, and Enterococcus faecium FAIR-E 198 and two commercial starter cultures. Initially, the sensibility in vitro of the starter to bacteriocinogenic cultures by an agar well diffusion assay was determined. Only Lc. lactis subsp. lactis ATCC 11454 was able to cause the inhibition of both starters. During the associative growth in milk at $35^{\circ} \mathrm{C}$, the bacteriocinogenic cultures did not affect the lactic acid production due to the starter cultures. Futhermore, the starter cultures provided a significant increase in the activity of pediocina AcH and enterocin FAIR-E 198. They also suppressed the nisin activity. Among all lactic cultures, Lb. plantarum ALC 01 showed the highest aminopeptidase activity ( 0,226 to 0,390 ). Therefore, according to these results $L$ b. plantarum ALC 01 and E. faecium FAIR-E 198 showed growth compatibility characteristics with the starter cultures and thus can be used as adjunct cultures in cheese making.
\end{abstract}

Keywords: bacteriocin; aminopeptidase; cheese.

\section{Introdução}

As bacteriocinas produzidas por bactérias lácticas têm despertado o interesse da indústria de alimentos como conservantes naturais, visto que apresentam habilidade de inibir o desenvolvimento de muitos microrganismos deteriorantes e patogênicos, incluindo Listeria monocytogenes, Staphylococcus aureus, Bacillus cereus e Clostridium botulinum (DE VUYST; VANDAMME, 1994). Outra aplicação interessante das culturas bacteriocinogênicas e suas bacteriocinas é a redução do período de maturação de queijos, resultante da liberação de aminopeptidases intracelulares na matriz do queijo, em decorrência da lise celular do fermento láctico promovida por estas culturas, contribuindo com a proteólise e formação de flavour desejáveis (MORGAN et al., 2002).
Existem muitas controvérsias na literatura científica sobre a capacidade acidificante e atividade de aminopeptidases das culturas produtoras de bacteriocinas. Andrighetto et al. (2001) e Sarantinopoulos et al. (2001) relataram baixa atividade acidificante de culturas bacteriocinogênicas, e Oumer et al. (2001b) e Garde et al. (2002) não observaram alteração significativa do pH de queijo Hispânico tanto na presença de E. faecalis quanto na de Lc. lactis subsp. lactis. Contudo, Oumer et al. (2001a) e Ávila et al. (2005a) verificaram alteração no pH de leite e queijo quando empregaram culturas bacteriocinogênicas.

Com relação à atividade de aminopeptidases, Ávila et al. (2005b) encontraram baixa atividade utilizando culturas bacterio-

Recebido para publicação em 22/8/2007

Aceito para publicação em 3/7/2008 (002765)

${ }^{1}$ Faculdade de Engenharia de Alimentos - FEA, UNICAMP, R. Monteiro Lobato, 80, CP 6121, CEP 13083-862, Campinas - SP, Brasil

2 Instituto de Tecnologia de Alimentos - ITAL, Av. Brasil 2880, Jd. Chapadão, CEP 13070-178, Campinas - SP, E-mail: mnascimento@ital.sp.gov.br

${ }^{*}$ A quem a correspondência deve ser enviada 
cinogênicas em leite, enquanto Garde et al. (2006) e Oumer et al. (2001b) relataram aumento da atividade de aminopeptidases em queijos fabricados com culturas produtoras de bacteriocinas.

Para determinar a viabilidade de aplicação de culturas bacteriocinogênicas na fabricação de queijos, como culturas iniciadoras ou adjuntas, Lc. lactis subsp. lactis ATCC 11454, Lb. plantarum ALC 01 e E. faecium FAIR-E 198 foram avaliadas quanto à capacidade de inibição in vitro de duas marcas comerciais de fermento láctico. Também, foram estudadas as capacidades de acidificação e de produção de bacteriocina durante cocultivo em leite desnatado destas culturas com os fermentos lácticos comerciais. Além disso, foi determinada a atividade de aminopeptidases.

\section{Material e métodos}

\subsection{Origem e manutenção dos microrganismos}

Foram avaliadas as culturas produtoras de bacteriocinas, Lactobacillus plantarum ALC 01, produtora de pediocina AcH e isolada de queijo Munster (ENNAHAR et al., 1996), Enterococcus faecium FAIR-E 198, produtora de enterocina e isolada de queijo Feta (ACA-DC 1618, Universidade de Agricultura de Atenas, Atenas, Grécia) e Lactococcus lactis subsp. lactis ATCC 11454, produtora de nisina (BCCM-LMG Bacteria Collection, Gent, Bélgica). Foram utilizadas duas diferentes marcas comerciais (A e B) de fermento mesofílico tipo $\mathrm{O}$, constituído por diferentes linhagens de Lc. lactis subsp. lactis e Lc. lactis subsp. cremoris. Para a realização dos testes, todas as culturas foram propagadas duas vezes consecutivas em caldo MRS (Difco ${ }^{\circ}$, Sparks, EUA), com incubação a $30^{\circ} \mathrm{C}$ para Lc. lactis subsp. lactis e a $37^{\circ} \mathrm{C}$ para as demais culturas por 16 a 24 horas.

Listeria monocytogenes Scott A, fornecida pelo Banco de Culturas do Laboratório de Higiene (Faculdade de Engenharia de Alimentos, Unicamp, Campinas, SP), foi utilizada como cultura indicadora para produção de bacteriocina.

\subsection{Determinação da sensibilidade do fermento láctico às culturas bacteriocinogênicas}

A sensibilidade dos fermentos lácticos comerciais às culturas produtoras de bacteriocinas foi avaliada in vitro, utilizandose o método de difusão em ágar por inoculação em poços, adaptado de Tagg e McGiven (1971).

Em $20 \mathrm{~mL}$ de ágar MRS (Difco $\left.{ }^{\circ}\right)$ semi-sólido (0,9\% ágar), foi inoculado $0,2 \mathrm{~mL}$ das suspensões dos fermentos lácticos comerciais $\left(10^{6}-10^{7}\right.$ UFC. $\left.\mathrm{mL}^{-1}\right)$, resultando em uma população entre $10^{4}$ e $10^{5}$ UFC.mL $\mathrm{mL}^{-1}$. Após solidificação, foram feitos três orifícios de $5 \mathrm{~mm}$ de diâmetro no ágar e estes foram inoculados com $50 \mu \mathrm{L}$ dos sobrenadantes obtidos por centrifugação ( $7500 \times$ g por 20 minutos a $4{ }^{\circ} \mathrm{C}$ ) a partir das culturas bacteriocinogênicas. Antes da utilização, os sobrenadantes tiveram seu $\mathrm{pH}$ ajustado para 6,5 e foram esterilizados por filtração em membrana filtrante $0,22 \mu \mathrm{m}$ (Millipore ${ }^{\circ}$, Carrigtwohill, Irlanda) (MORENO, 1995). As placas foram incubadas a $35^{\circ} \mathrm{C} / 24$ horas e analisadas quanto à presença de halos de inibição ao redor dos orifícios inoculados. Os testes foram realizados em triplicata.

\subsection{Determinação da capacidade acidificante e produção de bacteriocinas durante desenvolvimento associativo das culturas bacteriocinogênicas com os fermentos lácticos} Inoculação dos fermentos lácticos e das culturas
bacteriocinogênicas

Os fermentos lácticos em concentração de $1 \%(200 \mu \mathrm{L})$ foram inoculados em tubos de ensaio contendo $20 \mathrm{~mL}$ de leite desnatado reconstituído (LDR) a 10\%. Em seguida, foram adicionadas as culturas produtoras de bacteriocinas nas concentrações $0,1 \%(20 \mu \mathrm{L})$ e $0,5 \%(100 \mu \mathrm{L})$ e os tubos foram incubados a $35^{\circ} \mathrm{C} / 24$ horas (adaptado de OUMER et al., 2001a). Foi utilizado como controle LDR 10\% inoculado apenas com os fermentos lácticos ou com as culturas bacteriocinogênicas.

\section{Determinação da atividade acidificante}

$\mathrm{O}$ pH de cada cultivo foi determinado em pHmetro (Hanna Instruments HI9110, Singapura) após 8 e 24 horas de incubação a $35^{\circ} \mathrm{C}$.

\section{Determinação do título das bacteriocinas}

O título das bacteriocinas foi determinado pelo método de diluição crítica, adaptado de Mayr-Harting et al. (1972). Os sobrenadantes dos cultivos das culturas bacteriocinogênicas foram preparados conforme o item 2.2. Em seguida, foram diluídos sucessivamente na proporção de 1:2 em solução tampão fosfato de sódio $10 \mathrm{mM}$ a pH 7,0, utilizando placas de microtitulação. Então, $10 \mu \mathrm{L}$ de cada diluição foram depositados sobre placas contendo TSA-YE $\left(\mathrm{Difco}^{\circ}\right)$ semissólido ( $0,9 \%$ ágar), previamente inoculado com $0,2 \mathrm{~mL}$ de cultivo de L. monocytogenes Scott A $\left(10^{6}-10^{7} \mathrm{UFC} . \mathrm{mL}^{-1}\right)$, que foi utilizada como microrganismo indicador. As placas foram incubadas a $35^{\circ} \mathrm{C} / 24$ horas. $\mathrm{O}$ título de bacteriocina, expresso em unidade arbitrária de bacteriocina por mililitro (UA. $\mathrm{mL}^{-1}$ ), foi definido como a recíproca da maior diluição que apresentou halo de inibição, multiplicada por 100.

\subsection{Determinação da atividade de aminopeptidase}

Após incubação em caldo MRS (Difco ${ }^{\circ}$ ) por 24 horas a $30^{\circ} \mathrm{C}$ (Lc. lactis subsp. lactis ATCC 11454 e fermentos lácticos) e a $37^{\circ} \mathrm{C}$ ( Lb. plantarum ALC 01 e E. faecium FAIR-E 198), os cultivos foram centrifugados (Centrífuga Digital CIENTEC - CT 6000R - EQ - TL. 249, Palo Alto, EUA) a 5000 x g por 15 minutos a $4{ }^{\circ} \mathrm{C}$. O concentrado celular obtido foi triturado com alumina $\left(\right.$ Sigma $^{\circ}$, St Louis, EUA) adicionada na proporção de 1:2 (DAKO et al., 1995). Em seguida, o material foi transferido para um tubo de microcentrífuga contendo pérolas de vidro e, então, submetido à agitação por 3 ciclos de 1 minuto (BOUTROU et al., 1998). Após centrifugação a 20000 x g por 10 minutos a $4{ }^{\circ} \mathrm{C}$, o sobrenadante foi removido e o extrato enzimático foi reservado para análise.

A atividade de aminopeptidases foi determinada através da medida da extensão da hidrólise dos substratos cromogênicos: alanina-p-nitroanilida (Ala-p-NA, Sigma ${ }^{\circ}$, arginina-p-nitroanilida (Arg-p-NA, Sigma ${ }^{\circ}$ ), leucina- $p$-nitroanilida (Leu-p-NA, 
Sigma ${ }^{\circledR}$ ) e lisina- $p$-nitroanilida (Lys-p-NA, Sigma ${ }^{\circ}$ ), segundo o método descrito por Garde et al. (1997). A mistura de reação foi composta por $0,4 \mathrm{~mL}$ do extrato enzimático, $0,5 \mathrm{~mL}$ de tampão

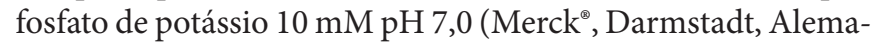
nha) e $0,1 \mathrm{~mL}$ de substrato cromogênico $25 \mathrm{mM}$ dissolvido em metanol. Após incubação a $35^{\circ} \mathrm{C} / 4$ horas, a absorbância foi mensurada a $410 \mathrm{~nm}$ em Espectrofotômetro DU-70 (Beckman Coulter ${ }^{\circ}$, Fullerton, EUA). A unidade de atividade enzimática foi definida como a variação de 0,01 unidade de absorbância em 1 minuto $(0,01 \mathrm{U} / \mathrm{min})$.

\subsection{Análise estatística}

A análise de variância paramétrica (ANOVA) e a comparação de média pelo teste de Tuckey ao nível de significância de 95\% foram utilizadas com a finalidade de avaliar estatisticamente os resultados obtidos a partir de diferentes culturas lácticas.

\section{Resultados e discussão}

\subsection{Sensibilidade dos fermentos lácticos às culturas bacteriocinogênicas}

Foram avaliadas duas diferentes marcas comerciais de fermento mesofílico tipo O, constituído por Lc. lactis subsp. lactis e Lc. lactis subsp. cremoris, quanto à sensibilidade às bacteriocinas produzidas por Lc. lactis subsp. lactis ATCC 11454, Lb. plantarum ALC 01 e E. faecium FAIR-E 198. Lc. lactis subsp. lactis ATCC 11454 promoveu zona de inibição de $6 \mathrm{~mm}$ em ambas as marcas de fermento láctico. Outros autores já haviam mencionado a sensibilidade de Lc. lactis subsp. lactis e Lc. lactis subsp. cremoris às bacteriocinas produzidas por linhagens homólogas (CONVENTRY et al., 1997, BENKERROUM et al., 2002, ELOTMANI et al., 2002). Já Lb. plantarum ALC 01 e E. faecium FAIR-E 198 não demonstraram atividade sobre os fermentos avaliados, confirmando os relatos de Franz et al. (1996), Ennahar et al. (1996), Leroy et al. (2003) e Alvarado et al. (2005).

\subsection{Determinação da capacidade acidificante e da produção de bacteriocinas durante desenvolvimento associativo}

\section{Capacidade acidificante}

As culturas bacteriocinogênicas avaliadas apresentaram lenta produção de ácido láctico, uma vez que, após 8 horas a $35^{\circ} \mathrm{C}$, os valores médios de $\mathrm{pH}$ do leite variaram entre 6,27 e $6,34(\Delta \mathrm{pH} 0,11-0,18)$ e entre 6,04 e $6,13(\Delta \mathrm{pH} 0,32-0,41)$ para concentrações de 0,1 e $0,5 \%$ de culturas bacteriocinogênicas, conforme Tabela 1. Estes resultados condizem com alguns relatos da literatura (ROBERTS et al., 1992, ANDRIGHETTO et al., 2001, SARANTINOPOULOS et al., 2001) que afirmam que culturas produtoras de bacteriocinas não apresentam características tecnológicas satisfatórias para serem utilizadas isoladamente como fermentos lácticos na fabricação de queijos.

Ayad et al. (2004) pesquisaram a habilidade de produção de ácido e atividade de aminopeptidase em 755 linhagens de bactérias lácticas isoladas de leite e derivados. Sessenta por cento (60\%) dos Lc. lactis subsp. lactis mostraram média atividade aci- dificante (redução de 0,4 unidades após 3 a 5 horas). A maioria das linhagens de $L b$. plantarum demonstrou baixa capacidade acidificante (redução de 0,4 unidades após período maior que 5 horas) e as linhagens E. faecium apresentaram atividade acidificante variando entre baixa e média.

Após 24 horas, E. faecium FAIR-E 198 e Lb. plantarum ALC 01 apresentaram $\Delta \mathrm{pH}$ de 1,23 e de 1,15 quando empregados na concentração de $0,5 \%$. Lc. lactis subsp. lactis, porém, mesmo após o aumento da concentração de $0,1 \%$ para $0,5 \%$, manteve $\Delta \mathrm{pH}$ abaixo de 0,5. Ávila et al. (2005a), após 8 e 23 horas de incubação em leite, obtiveram valores mais altos de $\mathrm{pH}$ para $\mathrm{Lb}$. plantarum e $E$. faecium do que os observados no presente estudo e valores semelhantes ou inferiores aos verificados para $L c$. lactis subsp. lactis ATCC $11454 \mathrm{em}$ ambas as concentrações utilizadas.

A adição de Lb. plantarum ALC 01, E. faecium FAIR-E 198 e mesmo de Lc. lactis subsp. lactis ATCC 11454, cuja bacteriocina demonstrou inibição dos fermentos lácticos no teste de difusão em ágar por inoculação em poços, tanto a $0,1 \%$ quanto a $0,5 \%$, não afetou significativamente $(p>0,05)$ a produção de ácido láctico por ambos os fermentos analisados após $8 \mathrm{e}$ 24 horas de incubação a $35{ }^{\circ} \mathrm{C}$ (Tabela 1). Garde et al. (2002) e Oumer et al. (2001b) também não observaram alterações de pH em queijo Hispânico fabricado com culturas adjuntas produtoras de bacteriocinas. Contudo, Oumer et al. (2001a) obtiveram alteração significativa do $\mathrm{pH}$ do leite em pelo menos 4 diferentes amostras de fermentos mesofílicos quando associados a Lc. lactis subsp. lactis, Lb. plantarum e E. faecium.

O fato de Lc. lactis subsp. lactis ATCC 11454 promover inibição dos fermentos lácticos no teste de difusão em ágar e não afetar o desenvolvimento e consequente produção de ácido láctico destes durante cocultivo em leite pode ser atribuído a inúmeros fatores como velocidade de crescimento da cultura bacteriocinogênica em leite (NASCIMENTO, 2007), menor produção de bacteriocina em leite quando comparado ao meio de cultura (MORENO, 1995; NASCIMENTO, 2007) ou interação da bacteriocina com compostos do leite (DAESCHEL, 1990).

\section{Determinação da produção de bacteriocinas}

A Tabela 2 mostra a atividade das bacteriocinas produzidas por Lc. lactis subsp. lactis ATCC 11454, Lb. plantarum ALC 01 e E. faecium FAIR-E 198, em duas concentrações de inóculos $(0,1 \%$ e $0,5 \%)$, após 24 horas de incubação a $35^{\circ} \mathrm{C}$ em leite, em cultivo puro e em desenvolvimento associativo com os fermentos lácticos comerciais A e B. Nenhuma produção de bacteriocina foi detectada para os fermentos lácticos analisados.

Em cultivo puro, as três culturas bacteriocinogênicas demonstraram aumento da atividade de bacteriocina, quando a concentração foi elevada de $0,1 \%$ para $0,5 \%$. O resultado mais expressivo foi detectado para $L b$. plantarum ALC 01, cuja atividade passou de $50 \mathrm{UA} \cdot \mathrm{mL}^{-1}$ para $400 \mathrm{UA} \cdot \mathrm{mL}^{-1}$ com o aumento da concentração do cultivo. A associação dos fermentos lácticos A e B com Lb. plantarum ALC 01 e E. faecium FAIR-E 198, em ambas as concentrações, proporcionou significativo aumento da atividade das bacteriocinas destas linhagens. Na concentração de $0,5 \%$, houve um aumento da atividade de 400 para $800 \mathrm{UA} \cdot \mathrm{mL}^{-1}$ para Lb. plantarum ALC 01 e de 100 para 400 a $800 \mathrm{UA} \cdot \mathrm{mL}^{-1}$ para 
E. faecium FAIR-E 198. Uma possível explicação para este fato seria a rápida degradação das caseínas promovida pelas proteinases dos fermentos lácticos, disponibilizando, assim, nutrientes para o desenvolvimento mais rápido das culturas adjuntas e consequentemente aumento da produção de bacteriocina. Esta hipótese teve como base os resultados obtidos por Moreno et al. (2002) que mencionaram que a baixa atividade proteolítica dos enterococos prejudicaria a produção de bacteriocinas, devido à indisponibilidade de nutrientes para o desenvolvimento microbiano, e por Sarantinopoulos et al. (2002) que obtiveram maior taxa de crescimento e maior produção de bacteriocina (100 UA.mL ${ }^{-1}$ ) por E. faecium FAIR-E 198 quando suplementaram o leite desnatado com $1,4 \%$ de caseína hidrolisada.

Lc. lactis subsp. lactis ATCC $11454 \mathrm{em}$ cultivo puro a $0,5 \%$ apresentou 100 UA. $\mathrm{mL}^{-1}$ de atividade de nisina sobre L. monocytogenes Scott A, contudo não foi observada atividade desta bacteriocina quando a linhagem produtora foi associada aos fermentos lácticos. Esta ausência de atividade pode estar relacionada à não produção de nisina pela linhagem, devido às suas condições de desenvolvimento durante cocultivo em leite (NASCIMENTO, 2007) ou à degradação da bacteriocina por proteases liberadas pelo fermento, como observado por Giraffa et al. (1995) utilizando E. faecium 7C5 em cocultivo com fermento comercial.

\subsection{Determinação da atividade de aminopeptidase}

A medida da atividade de aminopeptidases livres no extrato de queijo constitui-se numa importante fonte de informação não somente para avaliar a ocorrência de autólise como também para determinar a contribuição da microbiota nas reações proteolíticas envolvidas na maturação.

No sentido de determinar a atividade proteolítica, as culturas bacteriocinogênicas e os fermentos lácticos foram caracterizados quanto à atividade de aminopeptidase sobre os substratos cromogênicos Ala- $p$-NA, Arg- $p$-NA, Leu- $p$-NA e Lys- $p$-NA. Pelos resultados apresentados na Tabela 3 , verifica-se que, dentre as culturas avaliadas, $L b$. plantarum ALC 01 apresentou a maior atividade específica $(0,226$ a 0,390$)$ sobre todos os substratos utilizados. Dako et al. (1995) também observaram

Tabela 1. Valores de pH de LDR 10\% inoculado com 0,1\% e 0,5\% de Lc. lactis subsp. lactis ATCC 11454, Lb. plantarum ALC 01, E. faecium FAIR-E 198 e fermentos lácticos (1\%) após 8 e 24 horas de incubação a $35^{\circ} \mathrm{C}$.

\begin{tabular}{|c|c|c|c|c|}
\hline \multirow[t]{3}{*}{ Culturas e fermentos lácticos } & \multicolumn{4}{|c|}{$\mathrm{pH}$ do leite } \\
\hline & \multicolumn{2}{|c|}{$0,1 \%$ cult. bacterioc. } & \multicolumn{2}{|c|}{$0,5 \%$ cult. bacterioc. } \\
\hline & 8 horas & 24 horas & 8 horas & 24 horas \\
\hline Fermento A & $5,10^{\mathrm{b} * *}$ & $4,24^{\mathrm{d}}$ & $4,90^{\mathrm{b}}$ & $4,26^{\mathrm{b}}$ \\
\hline Fermento A + E. faecium FAIR-E 198 & $5,02^{\mathrm{b}}$ & $4,22^{\mathrm{d}}$ & $4,74^{\mathrm{b}}$ & $4,18^{\mathrm{b}}$ \\
\hline Fermento A + Lb. plantarum ALC 01 & $5,02^{\mathrm{b}}$ & $4,23^{\mathrm{d}}$ & $4,76^{\mathrm{b}}$ & $4,15^{\mathrm{b}}$ \\
\hline Fermento A + Lc. lactis subsp. lactis ATCC 11454 & $5,03^{\mathrm{b}}$ & $4,29^{\mathrm{d}}$ & $4,87^{\mathrm{b}}$ & $4,27^{\mathrm{b}}$ \\
\hline Fermento B & $5,06^{\mathrm{b}}$ & $4,24^{\mathrm{d}}$ & $4,89^{\mathrm{b}}$ & $4,25^{\mathrm{b}}$ \\
\hline Fermento B + E. faecium FAIR-E 198 & $4,95^{\mathrm{b}}$ & $4,24^{\mathrm{d}}$ & $4,80^{\mathrm{b}}$ & $4,21^{\mathrm{b}}$ \\
\hline Fermento B + Lb. plantarum ALC 01 & $4,97^{\mathrm{b}}$ & $4,24^{\mathrm{d}}$ & $4,84^{\mathrm{b}}$ & $4,20^{\mathrm{b}}$ \\
\hline Fermento B + Lc. lactis subsp. lactis ATCC 11454 & $5,00^{\mathrm{b}}$ & $4,27^{\mathrm{d}}$ & $4,80^{\mathrm{b}}$ & $4,26^{\mathrm{b}}$ \\
\hline E. faecium FAIR-E 198 & $6,27^{\mathrm{a}}$ & $5,72^{\mathrm{c}}$ & $6,13^{\mathrm{a}}$ & $5,22^{\mathrm{a}}$ \\
\hline Lb. plantarum ALC 01 & $6,34^{\mathrm{a}}$ & $6,10^{\mathrm{a}}$ & $6,08^{\mathrm{a}}$ & $5,30^{\mathrm{a}}$ \\
\hline Lc. lactis subsp. lactis ATCC 11454 & $6,28^{\mathrm{a}}$ & $5,97^{\mathrm{b}}$ & $6,04^{\mathrm{a}}$ & $5,99^{\mathrm{a}}$ \\
\hline
\end{tabular}

${ }^{*} \mathrm{pH}$ inicial do leite $=6,45 ; \mathrm{e}^{* *}$ médias seguidas pela mesma letra não diferem estatisticamente entre si $(\mathrm{p}>0,05)$.

Tabela 2. Atividade das bacteriocinas determinada pelo método de diluição crítica, utilizando Listeria monocytogenes Scott A como cultura indicadora.

\begin{tabular}{lrr}
\hline \multicolumn{1}{c}{ Culturas e fermentos lácticos } & \multicolumn{2}{c}{ Atividade de bacteriocina $\left(\text { UA.mL } \mathrm{mL}^{-1}\right)^{*}$} \\
\cline { 2 - 3 } & $0,1 \%$ cult. bacterioc. & 0 \\
Fermento A & 0 & 0 \\
Fermento B & 0 & 100 \\
E. faecium FAIR-E 198 & 0 & 400 \\
Fermento A + E. faecium FAIR-E 198 & 400 & 800 \\
Fermento B + E. faecium FAIR-E 198 & 200 & 400 \\
Lb. plantarum ALC 01 & 50 & 800 \\
Fermento A + Lb. plantarum ALC 01 & 400 & 800 \\
Fermento B + Lb. plantarum ALC 01 & 300 & 100 \\
Lc. lactis subsp. lactis ATCC 11454 & 0 & 0 \\
Fermento A + Lc. lactis subsp. lactis ATCC 11454 & 0 & 0 \\
Fermento B + Lc. lactis subsp. lactis ATCC 11454 & 0 & 0 \\
\hline
\end{tabular}

${ }^{\star}$ Unidade arbitrária de bacteriocina por mililitro $\left(U A \cdot \mathrm{mL}^{-1}\right)=$ recíproca da maior diluição que apresentou halo de inibição multiplicada por 100 . 
Tabela 3. Atividade de aminopeptidases das culturas bacteriocinogênicas e dos fermentos lácticos comerciais.

\begin{tabular}{lccc}
\hline Culturas e fermentos lácticos & \multicolumn{3}{c}{ Unidade de atividade enzimática } \\
\cline { 2 - 4 } & Ala- $p$-Na ${ }^{*}$ & Arg- $p$-Na & Leu- $p$-Na \\
\hline Fermento A & 0,068 & 0,046 & 0,054 \\
Fermento B & 0,092 & 0,057 & 0,059 \\
E. faecium FAIR-E 198 & 0,081 & 0,078 & 0,032 \\
Lb. plantarum ALC 01 & 0,256 & 0,053 & 0,053 \\
Lc. lactis subsp. lactis ATCC 11454 & 0,134 & 0,050 & 0,226 \\
\end{tabular}

${ }^{\star}$ Unidade de atividade enzimática $=$ variação de 0,01 unidade de absorbância em 1 minuto $(0,01 \mathrm{U} / \mathrm{min}) ; \mathrm{e}^{\star *}$-p-Na: $p$-nitroanilida.

maior atividade de aminopeptidases ( 5 a 100 vezes) no gênero Lactobacillus quando comparado a Lactococcus e Pediococcus. Baseado nestes resultados, o emprego desta linhagem não seria indicado para queijos frescos como o Minas Frescal, já que poderia promover a descaracterização do produto através do aumento da proteólise. Porém, para queijos maturados, sua adição seria desejável, pois contribuiria para a aceleração da maturação, conforme observado por Morgan et al. (2002) para outras linhagens bacteriocinogênicas.

Para E. faecium FAIR-E 198 e Lc. lactis subsp. lactis ATCC 11454, foi encontrada atividade entre 0,053 e 0,092 e entre 0,035 e 0,134 , respectivamente. Por se tratar de atividades relativamente baixas, estas linhagens não promoveriam aumento na proteólise, podendo ser empregadas como adjuntas ao fermento láctico tanto para queijos frescos quanto para maturados. Sarantinopoulos et al. (2001), avaliando esta mesma linhagem de E. faecium, em uma escala de 0 a 4 de atividade, encontraram 2 para leucina e zero para lisina. Em um estudo realizado por Ayad et al. (2004), 50\% das linhagens de Lactococcus analisadas, 70\% de Lactobacillus e 68\% de Enterococcus apresentaram baixa atividade de aminopeptidases.

Ambas as marcas de fermento láctico demonstraram baixa atividade de aminopeptidases, com valores entre 0,032 e 0,054 para a marca A e entre 0,057 e 0,092 para a marca B. Estes resultados condizem com os relatados por Oumer et al. (2001a), portanto, estes fermentos apresentam capacidade acidificante, porém baixa atividade proteolítica, de acordo com sua classificação comercial de fermento mesofílico tipo $\mathrm{O}$.

\section{Conclusões}

As três culturas bacteriocinogênicas apresentaram baixa capacidade acidificante, não podendo ser empregadas como culturas iniciadoras. Com exceção da nisina que foi suprimida, a produção de pediocina $\mathrm{AcH}$ e enterocina foi potencializada pela presença dos fermentos lácticos. Dentre todas as culturas lácticas, $L b$. plantarum ALC 01 apresentou a maior atividade de aminopeptidases. Portanto, considerando as características tecnológicas avaliadas, $L b$. plantarum ALC 01 e E. faecium FAIR-E 198 são indicadas como culturas adjuntas, visando aumentar a segurança microbiológica de queijos maturados e frescos, respectivamente.

\section{Agradecimentos}

Ao Dr. Effie Tsakalidou (Universidade de Agricultura de Atenas, Grécia) e ao Dr. Siegfried Scherer (Universidade Técnica de Munique, Alemanha) pela concessão das linhagens E. faecium FAIR-E 198 e Lb. plantarum ALC 01. À Fundação de Amparo à Pesquisa do Estado de São Paulo (FAPESP) e ao Conselho Nacional de Desenvolvimento Científico e Tecnológico (CNPq) pelo suporte financeiro.

\section{Referências bibliográficas}

ALVARADO, C. et al. Anti-Listeria monocytotgenes bacteriocin-like inhibitory substances from Enterococcus faecium UQ31 isolated from artisan mexican-style cheese. Current Microbiology, v. 51, n. 2, p. 110-115, 2005.

ANDRIGHETTO, C. et al. Phenotypic and genetic diversity of enterococci isolated from Italian cheese. Journal of Dairy Research, v. 68, n. 2, p. 303-316, 2001.

ÁVILA, M. et al. Influence of a bacteriocin-producing lactic culture on proteolysis and texture of Hispánico cheese. International Dairy Journal, v. 15, n. 2, p. 145-153, 2005 a.

ÁVILA, M. et al. Effect of milk inoculation with bacteriocin-producing lactic acid bacteria on a Lactobacillus helveticus adjunct cheese culture. Journal of Food Protection, v. 68, n. 5, p. 1026-1033, 2005b.

AYAD, E. H. E. et al. Selection of wild lactic acid bacteria isolated from tradicional Egyptian dairy products according to production and technological criteria. Food Microbiology, v. 21, n. 6, p. 715-725, 2004.

BENKERROUM, N. et al. Biocontrol of Listeria monocytogenes in model cultured milk by in situ bacteriocin production from Lactococcus lactis lactis. International Journal of Dairy Technology, v. 55, n. 3, p. 145-151, 2002.

BOUTROU, R. et al. Simple tests for predicting the lytic behavior and proteolytic activity of lactococcal strains in cheese. Journal of Dairy Science, v. 81, n. 9, p. 2321-2328, 1998.

CONVENTRY, M. J. et al. Detection of bacteriocins of lactic acid bacteria isolated from foods and comparison with pediocina and nisin. Journal of Applied Microbiology, v. 83, n. 11, p. 246-258, 1997.

DAESCHEL, M. A. Application of bacteriocin in food systems. In: BILLS, D. D.; KUNG, S. (Ed.). Biotechnology and Food Safety. Boston: Butterworth-heinemann, 1990. p. 55-74.

DAKO, E. et al. Autolytic properties and aminopeptidase activities of lactic acid bacteria. Food Research International, v. 28, n. 5, p. 503-509, 1995.

De VUYST, L.; VANDAMME E. J. Bacteriocins of lactic acid bacteria. Londres: Blackie Academic \& Professional, 1994. 539p.

ELOTMANI, F. et al. Characterization of anti-Listeria monocytogenes bacteriocins from Enterococcus faecalis, Enterococcus faecium and Lactococcus lactis strains isolated from Raib, a Moroccan tradicional fermented milk. Current Microbiology, v. 44, n. 1, p. 10-17, 2002. 
ENNAHAR, S. et al. Production of pediocin AcH by Lactobacillus plantarum WHE92 isolated from cheese. Applied and Environmental Microbiology, v. 62, n. 12, p. 4381-4387, 1996.

FRANZ, C. M. A. P.; SCHILlINGER, U.; HOLZAPFEL, W. H. Production and characterization of enterocin 900, a bacteriocin produced by Enterococcus faecium BFE 900 from black olives. International Journal of Food Microbiology, v. 29, n. 2-3, p. 255-270, 1996.

GARDE, S. et al. Acceleration of flavour formation in cheese by a bacteriocin-producing adjunct lactic culture. Biotechnology Letters, v. 19, n. 10, p. 1011-1014, 1997.

GARDE, S. et al. Proteolysis in Hispánico cheese manufactured using a mesophilic starter, a thermophilic starter, and bacteriocinproducing Lactococcus lactis lactis INIA 415 adjunct culture. Journal of Agricultural and Food Chemistry, v. 50, n. 10, p. 34793485, 2002.

GARDE, S. et al. Proteolysis of Hispânico cheese manufactured using lacticin 481-producing Lactococcus lactis spp. lactis INIA 639. Journal of Dairy Science, v. 89, n. 3, p. 840-849, 2006.

GIRAFFA, G. Enterococcal bacteriocins: their potential as antiListeria factors in dairy technology. Food Microbiology, v. 12, n. 12, p. 291-299, 1995.

LEROY, F.; FOULQUIÉ MORENO, M. R.; De VUYST, L. Enterococcus faecium RZS C5, an interesting bacteriocin producer to be used as a co-culture in food fermentation. International Journal of Food Microbiology, v. 88, n. 2-3, p. 235-240, 2003.

MAYR-HARTING, A.; HEDGES, A. J.; BERKELEY, C. W. Methods for studying bacteriocins. In: NORRIS, J. R.; RIBBONS, D. W. (Eds.). Methods in Microbiology. New York: Academic Press Inc., 1972. v.7.

MORENO, I. Ocorrência e caracterização de bacteriocinas de lactococos e sua utilizacao no processamento de queijo minas frescal. 1995, 190p. Dissertação (Mestrado em Ciência de Alimentos), Faculdade de Ciências Farmacêuticas, USP.
MORENO, M. R .F. et al. Applicability of a bacteriocin-producing Enterococcus faecium as a co-culture in Cheddar cheese manufacture. International Journal of Food Microbiology, v. 81, n. 1, p. 73-84, 2002.

MORGAN, S. M. et al. The design of a three strain starter system for Cheddar cheese manufacture exploiting bacteriocin-induced starter lysis. International Dairy Journal, v. 12, n. 12, p. 985-993, 2002.

NASCIMENTO, M. S. Caracterização da atividade antimicrobiana e tecnológica de três culturas bacteriocinogênicas e avaliação de sua eficiência no controle de Listeria monocytogenes, Staphylococcus aureus e Bacillus cereus em queijo minas frescal. Campinas, 2007. 184p. Tese (Doutorado em Tecnologia de Alimentos), Faculdade de Engenharia de Alimentos, UNICAMP.

OUMER, A. et al. The effects of cultivating lactic starter cultures with bacteriocin-producing lactic acid bacteria. Journal of Food Protection, v. 64, n. 1, p. 81-86, 2001a.

OUMER, A. et al. Proteolysis and formation of volatile compounds in cheese manufactured with a bacteriocina-producing adjunct culture. Journal of Dairy Research, v. 68, n. 1, p. 117-129, $2001 \mathrm{~b}$.

ROBERTS, R. F.; ZOTTOLA, E. A.; MCKAY, L. L. Use of nisinproducing starter culture suitable for Cheddar cheese manufacture. Journal of Dairy Science, v. 75, n. 9, p. 2353-2363, 1992.

SARANTINOPOULOS, P. et al. Biochemical properties of enterococci relevant to their technological performance. International Dairy Journal, v. 11, n. 8, p. 621-647, 2001.

SARANTINOPOULOS, P.; KALANTZOPOULOS, G.; TSAKALIDOU, E. Effect of Enterococcus faecium on microbiological, physicochemical and sensory characteristics of greek feta cheese. International Journal of Food Microbiology, v. 76, n. 1-2, p. 93-105, 2002.

TAGG, J. R.; MCGIVEN, A. R. Assay system for bacteriocins. Applied Microbiology, v. 21, n. 5, p. 943, 1971. 